\title{
Handgrip strength and health-related quality of life in elderly patients attending physiotherapy clinics
}

Janet Bong May Ing ${ }^{1}$, Bsc, Howell Menor ${ }^{1}$, Bsc, Naimah binti Wahab ${ }^{1}$, Bsc, Nur Rusyda binti Ishak ${ }^{1}$, Bsc, Mohamad Adam Bujang ${ }^{2}$, PhD, Fatin Ellisya Sapri ${ }^{2}$ Bsc

\begin{abstract}
Background. A progressive decrease in muscle mass and consequent muscle strength can lead to disability, morbidity, and mortality. This study aimed to determine the association between handgrip strength and health-related quality of life (HRQOL) in elderly patients with medical conditions.
\end{abstract}

Methods: Those aged $\geq 60$ years who attended the physiotherapy clinics between September and November 2016 were invited to participate. Handgrip strength was measured in $\mathrm{kg}$ using a Jamar Handgrip Dynamometer. The SF-36 health survey was used to assess HRQOL; lower scores represent greater disability.

Results: A total of 142 female and 87 male elderly patients participated. The most common medical condition was osteoarthritis (25.3\%), followed by cardiac problems $(20.5 \%)$, low back pain $(17.4 \%)$, others $(15.7 \%)$, stroke $(13.1 \%)$, fracture $(4.4 \%)$, and trigger finger $(3.5 \%)$. In males and females, the most common medical conditions were cardiac problems (36.8\%) and osteoarthritis (31.0\%), respectively. Compared with females, males had better handgrip strength (24.46 vs. $15.25 \mathrm{~kg}$, $\mathrm{p}<0.001$ ) and HRQOL in terms of most SF-36 sub-scores. In males, handgrip strength differed significantly in those with different medical conditions $(p=0.026)$; handgrip strength was highest in those with cardiac problems and lowest in those with osteoarthritis. In females, higher handgrip strength was associated with younger age-group ( $p=0.003$, analysis of covariance). In males, handgrip strength was positively correlated with all domains of SF-36. In females, handgrip strength was positively correlated with domains of physical functioning, role physical, social functioning, and physical component summary.

Conclusions: Lower handgrip strength is associated with poor HRQOL, particularly physical functioning, among Malaysian elderly patients with medical conditions. Handgrip strength can be used to determine the physical condition of elderly patients.

Key words: Aged; Hand strength; Quality of life

\section{ORIGINAL ARTICLE}

\author{
Physiotherapy Department, Sarawak \\ Heart Centre, Malaysia \\ 2 Clinical Research Centre, Sarawak \\ General Hospital, Malaysia
}

Correspondence to: Mohamad Adam Bujang, Clinical Research Centre, Sarawak General Hospital, Jalan Tun Ahmad Zaidi Adruce, Kuching, Sarawak, Malaysia.

Email:adam@crc.gov.my

\section{INTRODUCTION}

In Malaysia in 2016, 6.0\% (1.9 million) of a total population of 31.7 million were estimated to be elderly people. ${ }^{1}$ By 2030 , the proportion is expected to increase to $>15 \%$, according to the World Population Ageing Report 2015. ${ }^{2}$ Population ageing is a challenge to the healthcare system. ${ }^{3}$ Ageing is associated with a progressive decrease in muscle mass and strength ${ }^{4}$ that may lead to disability, morbidity, and mortality. 
Handgrip strength is a simple and good indicator of overall muscle strength., Elderly people with lower handgrip strength are more likely to have poorer self-reported general health and quality of life, as well as more falls and disability and impaired healthrelated quality of life (HRQOL), ${ }^{6,7}$ According to the American Society of Hand Therapists, the Jamar dynamometer is the gold standard for measuring handgrip strength, ${ }^{8}$ with good-to-excellent $(r>0.80)$ test-retest reproducibility, ${ }^{9}$ and excellent $(r=0.98)$ interrater reliability. ${ }^{10}$

HRQOL is defined as an individual's satisfaction or happiness with domains of life as far as they affect or are affected by health. ${ }^{11}$ The Short Form36 health survey (SF-36) is extensively used across all ages, widely translated, and sensitive to illness conditions. ${ }^{7,11}$

There are limited studies investigating the association of muscle strength with HRQOL in elderly people. Early detection of decreased muscle strength enables proper intervention to prevent deterioration. This study aimed to determine the association of handgrip strength with HRQOL in Malaysian older people.

\section{MATERIALS AND METHODS}

This study was approved by the Malaysia Ministry of Health Medical Research Ethics Committee. Informed consent from each participant was obtained. This cross-sectional study was carried out at two government hospitals in the Kuching and Kota Samarahan regions. Those aged $\geq 60$ years who attended the physiotherapy clinic at either hospital between September and November 2016 for a wide range of conditions were invited to participate. Those who had poor cognitive function (Mini-Mental State Examination score of $<15$ ) or were illiterate were excluded. Participants were interviewed by a trained research assistant using a case report form.

Handgrip strength was measured in $\mathrm{kg}$ using a Jamar Handgrip Dynamometer (Patterson Medical, UK). Patients were asked to sit on a chair with the shoulder adducted, elbow flexed at $90^{\circ}$, and middle fingertip resting on the inner handle of the hand dynamometer. Each hand was measured 3 times, and the highest measurement was used.
TABLE 1

Socio-demographic and clinical characteristics of elderly patients

\begin{tabular}{|c|c|c|}
\hline Variable & Male $(n=87)^{\star}$ & Female $(n=142)^{*}$ \\
\hline Mean \pm SD age, $y$ & $69.3 \pm 5.8$ & $68.5 \pm 6.3$ \\
\hline \multicolumn{3}{|l|}{ Age-group, y } \\
\hline $60-69$ & $47(54.0)$ & $90(63.4)$ \\
\hline $70-79$ & $34(39.1)$ & $42(29.6)$ \\
\hline$\geq 80$ & $6(6.9)$ & $10(7.0)$ \\
\hline \multicolumn{3}{|l|}{ Ethnicity } \\
\hline Malay & $31(35.6)$ & $28(19.7)$ \\
\hline Chinese & $40(46.0)$ & $100(70.4)$ \\
\hline Bumiputera Sarawak & $11(12.6)$ & $10(7.0)$ \\
\hline Others & $5(5.7)$ & $4(2.8)$ \\
\hline \multicolumn{3}{|l|}{ Education level } \\
\hline Primary & 29 (33.3) & $40(28.2)$ \\
\hline Secondary & $39(44.8)$ & $55(38.7)$ \\
\hline College/university & $14(16.1)$ & $16(11.3)$ \\
\hline Never been to school & $5(5.7)$ & $31(21.8)$ \\
\hline \multicolumn{3}{|l|}{ Marital status } \\
\hline Single & $5(5.7)$ & $12(8.5)$ \\
\hline Married & $78(89.7)$ & $102(71.8)$ \\
\hline Widowed & $4(4.6)$ & $28(19.7)$ \\
\hline \multicolumn{3}{|l|}{ Smoking history } \\
\hline Yes & 9 (10.3) & $1(0.7)$ \\
\hline No & $78(89.7)$ & 141 (99.3) \\
\hline \multicolumn{3}{|l|}{ Alcohol history } \\
\hline Yes & $11(12.6)$ & $8(5.6)$ \\
\hline No & $76(87.4)$ & $134(94.4)$ \\
\hline \multicolumn{3}{|l|}{ Diagnosis } \\
\hline Cardiac & $32(36.8)$ & $15(10.6)$ \\
\hline Stroke & $10(11.5)$ & $20(14.1)$ \\
\hline low back pain & $15(17.2)$ & 25 (17.6) \\
\hline Osteoarthritis & $14(16.1)$ & $44(31.0)$ \\
\hline Trigger finger & $2(2.3)$ & $6(4.2)$ \\
\hline Fracture & $4(4.6)$ & $6(4.2)$ \\
\hline Others & $10(11.5)$ & 26 (18.3) \\
\hline \multicolumn{3}{|l|}{ Body mass index } \\
\hline Underweight & $4(6.3)$ & $6(5.5)$ \\
\hline Normal & $29(46.0)$ & $49(44.5)$ \\
\hline Overweight & $22(34.9)$ & $40(36.4)$ \\
\hline Obese & $8(12.7)$ & 15 (13.6) \\
\hline Dyslipidaemia & $48(55.2)$ & 79 (55.6) \\
\hline Hypertension & 51 (58.6) & $88(62.0)$ \\
\hline Diabetes & $34(39.1)$ & $36(25.4)$ \\
\hline
\end{tabular}

* Data are presented as No. (\%) of participants unless otherwise stated 
The self-administered, bilingual SF-36 was used to assess HRQOL. It comprises the physical component summary and the mental component summary, with 36 items in 8 health domains: physical functioning, role physical, bodily pain, general health, vitality, social functioning, role emotional, and mental health. Total score ranges from 0 to 100; lower scores represent greater disability.

One-way analysis of variance was used to determine the association between patient characteristics and handgrip strength. Significant factors were further analysed using analysis of covariance. A post hoc test based on Fisher's least significant difference test was conducted to determine the significance in the pairing categories.

\section{RESULTS}

A total of 142 female and 87 male elderly patients participated (TABLE $\mathbf{1})$. The mean age was 68.8 years; $60 \%, 33 \%$, and $7 \%$ were in the age-groups of $60-69$ years, 70-79 years, and $\geq 80$ years, respectively. The most common medical condition was osteoarthritis (25.3\%), followed by cardiac problems (20.5\%), low back pain $(17.4 \%)$, others $(15.7 \%)$, stroke $(13.1 \%)$, fracture $(4.4 \%)$, and trigger finger (3.5\%). In males and females, the most common medical conditions were cardiac problems (36.8\%) and osteoarthritis $(31.0 \%)$, respectively.
Compared with females, males had better handgrip strength (24.46 vs. $15.25 \mathrm{~kg}, \mathrm{p}<0.001)$ and HRQOL in terms of SF-36 sub-scores of physical functioning ( 67.70 vs. $55.25, \mathrm{p}=0.001$ ), role physical ( 58.19 vs. $46.57, \mathrm{p}=0.003)$, bodily pain (70.21 vs. 57.05 , $\mathrm{p}<0.001)$, general health (63.40 vs. $58.51, \mathrm{p}=0.024)$, and mental health (76.21 vs. $71.20, \mathrm{p}=0.019)$, as well as physical component summary score (45.34 vs. 40.39, $\mathrm{p}<0.001)$ [TABLE 2].

In males, handgrip strength differed significantly in those with different medical conditions $(\mathrm{p}=0.026$, TABLE 3); handgrip strength was highest in those with cardiac problems and lowest in those with osteoarthritis. In females, higher handgrip strength was associated with younger age-group $(p<0.001)$, secondary education level $(\mathrm{p}=0.001)$, and absence of diabetes $(\mathrm{p}=0.036)$ in one-way analysis of variance (TABLE 3], but only age-group remained significant in analysis of covariance ( $\mathrm{p}=0.003$, TABLE 4$)$.

In males, handgrip strength was positively correlated with all domains of SF-36. In females, handgrip strength was positively correlated with domains of physical functioning, role physical, social functioning, and physical component summary (TABLE 5).

\section{DISCUSSION}

In our study, handgrip strength was moderately

TABLE 2

Comparison of health-related quality of life and handgrip strength between males and females

\begin{tabular}{llcc}
\hline Variable & Male $(\mathrm{n}=87)^{\star}$ & Female $(\mathrm{n}=142)^{\star}$ & $\mathrm{p}$ Value (independent $t$-test) \\
\hline SF-36 sub-score & & & \\
Physical functioning & $67.70 \pm 27.22$ & $55.25 \pm 25.10$ & 0.001 \\
Role physical & $58.19 \pm 31.69$ & $46.57 \pm 26.64$ & 0.003 \\
Social functioning & $77.59 \pm 26.08$ & $75.09 \pm 23.56$ & 0.456 \\
Vitality & $64.73 \pm 16.97$ & $60.62 \pm 17.74$ & 0.085 \\
Bodily pain & $70.21 \pm 25.90$ & $57.05 \pm 24.34$ & $<0.001$ \\
General health & $63.40 \pm 16.42$ & $58.51 \pm 15.36$ & 0.024 \\
Role emotional & $77.87 \pm 26.44$ & $74.53 \pm 27.32$ & 0.364 \\
Mental health & $76.21 \pm 15.42$ & $71.20 \pm 15.68$ & 0.019 \\
Physical component summary & $45.34 \pm 9.07$ & $40.39 \pm 8.08$ & $<0.001$ \\
Metal component summary & $51.90 \pm 9.44$ & $51.46 \pm 9.86$ & 0.737 \\
Handgrip strength, kg & $24.46 \pm 7.79$ & $15.25 \pm 4.70$ & $<0.001$ \\
\hline
\end{tabular}

* Data are presented as mean \pm standard deviation 
TABLE 3

Handgrip strength in terms of patient characteristics and medical conditions

\begin{tabular}{|c|c|c|c|c|}
\hline \multirow[t]{2}{*}{ Variable } & \multicolumn{2}{|c|}{ Male $(n=87)$} & \multicolumn{2}{|c|}{ Female $(n=142)$} \\
\hline & $\begin{array}{l}\text { Mean } \pm S D \text { handgrip } \\
\text { strength, kg }\end{array}$ & $p$ Value & $\begin{array}{l}\text { Mean } \pm S D \text { handgrip } \\
\text { strength, kg }\end{array}$ & $\mathrm{p}$ Value \\
\hline Age-group, y & & 0.285 & & $<0.001$ \\
\hline $60-69$ & $22.57 \pm 8.83$ & & $16.42 \pm 4.36$ & \\
\hline $70-79$ & $22.81 \pm 1.11$ & & $13.87 \pm 4.59$ & \\
\hline$\geq 80$ & $25.08 \pm 1.82$ & & $10.45 \pm 3.66$ & \\
\hline Ethnicity & & 0.664 & & 0.204 \\
\hline Malay & $24.18 \pm 6.68$ & & $13.64 \pm 4.95$ & \\
\hline Chinese & $25.41 \pm 8.29$ & & $15.73 \pm 4.58$ & \\
\hline Bumiputera Sarawak & $23.00 \pm 10.16$ & & $15.45 \pm 4.91$ & \\
\hline Others & $21.80 \pm 4.15$ & & $14.00 \pm 4.32$ & \\
\hline Education level & & 0.203 & & 0.001 \\
\hline Primary & $25.29 \pm 7.92$ & & $15.34 \pm 4.33$ & \\
\hline Secondary & $23.99 \pm 7.90$ & & $16.71 \pm 3.91$ & \\
\hline College/university & $26.32 \pm 6.35$ & & $15.13 \pm 5.96$ & \\
\hline Never been to school & $18.10 \pm 8.43$ & & $12.60 \pm 4.78$ & \\
\hline Marital status & & 0.751 & & 0.259 \\
\hline Single & $23.20 \pm 8.32$ & & $16.83 \pm 4.20$ & \\
\hline Married & $24.67 \pm 7.83$ & & $15.34 \pm 4.51$ & \\
\hline Widow/widower & $22.00 \pm 7.83$ & & $14.23 \pm 5.45$ & \\
\hline Smoking & & 0.783 & & 0.558 \\
\hline Yes & $23.78 \pm 6.74$ & & $18.00 \pm 0$ & \\
\hline No & $24.54 \pm 7.93$ & & $15.23 \pm 4.71$ & \\
\hline Alcohol drinking & & 0.868 & & 0.262 \\
\hline Yes & $24.09 \pm 8.05$ & & $17.06 \pm 2.91$ & \\
\hline No & $24.51 \pm 7.80$ & & $15.14 \pm 4.77$ & \\
\hline Medical condition & & $0.026^{\star}$ & & 0.411 \\
\hline Cardiac problems & $27.98 \pm 6.13$ & & $16.67 \pm 4.52$ & \\
\hline Stroke & $20.50 \pm 10.70$ & & $13.70 \pm 5.16$ & \\
\hline Low back pain & $24.40 \pm 6.67$ & & $16.00 \pm 4.27$ & \\
\hline Osteoarthritis & $20.25 \pm 7.23$ & & $15.53 \pm 5.07$ & \\
\hline Trigger finger & $23.25 \pm 12.37$ & & $16.50 \pm 4.28$ & \\
\hline Fracture & $25.75 \pm 8.88$ & & $15.00 \pm 5.51$ & \\
\hline Others & $22.85 \pm 7.36$ & & $14.17 \pm 3.98$ & \\
\hline Body mass index & & 0.757 & & 0.168 \\
\hline Underweight & $22.00 \pm 8.64$ & & $18.17 \pm 4.12$ & \\
\hline Normal & $23.60 \pm 7.86$ & & $14.80 \pm 4.24$ & \\
\hline Overweight & $25.36 \pm 8.05$ & & $16.39 \pm 4.36$ & \\
\hline Obese & $23.00 \pm 4.41$ & & $15.20 \pm 4.90$ & \\
\hline Dyslipidemia & & 0.242 & & 0.484 \\
\hline Yes & $25.34 \pm 7.98$ & & $15.49 \pm 4.20$ & \\
\hline No & $23.37 \pm 7.50$ & & $14.94 \pm 5.27$ & \\
\hline Hypertension & & 0.813 & & 0.190 \\
\hline Yes & $24.63 \pm 7.82$ & & $14.84 \pm 4.86$ & \\
\hline No & $24.22 \pm 7.85$ & & $15.91 \pm 4.38$ & \\
\hline Diabetes & & 0.464 & & 0.036 \\
\hline Yes & $23.69 \pm 7.43$ & & $13.83 \pm 4.54$ & \\
\hline No & $24.95 \pm 8.04$ & & $15.73 \pm 4.70$ & \\
\hline
\end{tabular}

\footnotetext{
* Least significant difference multiple test comparison: cardiac problems $>$ stroke $(p=0.007)$ and cardiac problems $>$ osteoarthritis $(p=0.002)$
} 
Ing et al

correlated with HRQOL in terms of physical component summary in males $(r=0.455, \mathrm{p}<0.001)$ and females $(r=0.372, \mathrm{p}<0.001)$. This finding is similar to those of another study that showed lower handgrip strength to be associated with increased prevalence of poor role physical score in men and increased prevalence of poor physical functioning in women. ${ }^{7}$ A positive association between handgrip strength and HRQOL suggests that handgrip strength can be a predictor of HRQOL in elderly people with health problems.

Handgrip strength was significantly greater in men than in women and gradually decreased with age. The maximum handgrip strength has been reported to be $28.8 \mathrm{~kg}$ and $18.9 \mathrm{~kg}$ respectively in healthy Malaysian elderly men and women. ${ }^{12}$ In our elderly men and women with medical conditions, the maximum handgrip strength was $24.46 \mathrm{~kg}$ and $15.25 \mathrm{~kg}$, which is 0.17 times weaker. Their medical conditions might have contributed to weaker handgrip strength. Patients with cardiac problems had stronger handgrip strength, whereas males with osteoarthritis and females with stroke had weakest handgrip strength. Different medical conditions contributed differently to handgrip strength $(\mathrm{p}<0.05)$ in males only; handgrip strength was higher in those with cardiac problems than with stroke $(\mathrm{p}=0.007)$ or

TABLE 4

Association of handgrip strength with age-group, education level, and presence of diabetes in female patients

\begin{tabular}{|c|c|c|c|}
\hline Factors & $\begin{array}{c}\text { Marginal means of } \\
\text { handgrip strength, kg }\end{array}$ & $p$ Value & $\begin{array}{l}\text { Least significant difference } \\
\text { multiple test comparison }\end{array}$ \\
\hline Age-group, y & & 0.003 & \\
\hline $60-69$ & 15.49 & & $1>2(0.002)$ \\
\hline $70-79$ & 13.74 & & $1>3(<0.001)$ \\
\hline$\geq 80$ & 10.61 & & $2>3(0.025)$ \\
\hline Education level & & 0.088 & \\
\hline Primary & 13.69 & & \\
\hline Secondary & 14.48 & & \\
\hline College/university & 13.09 & & \\
\hline Never been to school & 11.86 & & \\
\hline Diabetes & & 0.075 & \\
\hline Yes & 12.53 & & \\
\hline No & 14.03 & & \\
\hline
\end{tabular}

TABLE 5

Correlation between handgrip strength and health-related quality of life

\begin{tabular}{lccccc}
\hline SF-36 domain & \multicolumn{2}{c}{ Male $(\mathrm{n}=87)$} & \multicolumn{2}{c}{ Female $(\mathrm{n}=142)$} \\
\cline { 2 - 3 } \cline { 5 - 5 } & $r$ & $\mathrm{p}$ Value & & \multicolumn{1}{c}{$\mathrm{p}$ Value } \\
\hline Physical functioning & 0.484 & $<0.001$ & & 0.442 & $<0.001$ \\
Role physical & 0.464 & $<0.001$ & & 0.341 & $<0.001$ \\
Social functioning & 0.362 & 0.001 & & 0.171 & 0.042 \\
Vitality & 0.244 & 0.023 & & 0.123 & 0.144 \\
Bodily pain & 0.240 & 0.025 & & 0.157 & 0.062 \\
General health & 0.254 & 0.018 & & 0.067 & 0.427 \\
Role emotional & 0.321 & 0.002 & & 0.144 & 0.087 \\
Mental health & 0.284 & 0.008 & & 0.139 & 0.100 \\
Physical component summary & 0.455 & $<0.001$ & & 0.372 & $<0.001$ \\
Mental component summary & 0.217 & 0.044 & 0.041 & 0.624 \\
\hline
\end{tabular}


osteoarthritis $(\mathrm{p}=0.002)$.

Increasing age significantly decreased handgrip strength in women only $(\mathrm{p}<0.001)$ not men $(\mathrm{p}=0.285)$. This finding is consistent with studies that report a progressive decline in handgrip strength with age among elderly females, ${ }^{12,13}$ probably owing to lower body weight. ${ }^{14}$

One limitation of our study is the cross-sectional nature that cannot establish a causal relationship between handgrip strength and HRQOL. It is plausible that poor HRQOL could lead to inactivity and loss of muscle function. In addition, the sample size was small and the findings may not be generalisable to the entire population.

\section{CONCLUSION}

Lower handgrip strength is associated with poor HRQOL, particularly physical functioning, among Malaysian elderly patients with medical conditions. Handgrip strength can be used to determine the physical condition of elderly patients.

\section{ACKNOWLEDGEMENTS}

This study was supported by a grant from the Secretariat, National Institutes of Health, Ministry of Health, Malaysia. We would like to thank the Director General of Health Malaysia for his permission to publish this article and Miss Chien Joo Lim for her assistance in paper submission. The authors would like to express gratitude to the head of Sarawak Physiotherapy Profession, $\mathrm{Hj}$ Ismail Bin Damit, and our research assistants, Khor Sze Min and Nuranisa, for their assistance.

\section{DECLARATION}

The authors have no conflict of interest to disclose.

\section{REFERENCES}

1. Department of Statistics Malaysia (2016). Available from http:// www.dosm.gov.my. Accessed 25 May 2017.

2. United Nations Department of Economic and Social Affairs. World Population Ageing. 2015.

3. Ambigga,KS, Ramli AS, Suthahar A, Tauhid H, Clearihan L, Browning $\mathrm{C}$. Bridging the gap in ageing: translating policies into practice in Malaysian primary care. Asia Pac Fam Med 2011;10:2. Crossref

4. Giampaoli S, Ferrucci L, Cecchi F, et al. Hand-grip strength predicts incident disability in non-disabled older men. Age Ageing 1999;28:283-8. Crossref

5. Jeune B, Skytthe A, Cournil A, et al. Handgrip strength among nonagenarians and centenarians in three European regions. $J$ Gerontol A Biol Sci Med Sci 2006;61:707-12. Crossref

6. Roberts HC, Denison HJ, Martin HJ, et al. A review of the measurement of grip strength in clinical and epidemiological studies: towards a standardised approach. Age Ageing 2011;40:423-9. Crossref

7. Sayer AA, Syddall HE, Martin HJ, Dennison EM, Roberts HC, Cooper $\mathrm{C}$. Is grip strength associated with health-related quality of life? Findings from the Hertfordshire Cohort Study. Age Ageing 2006;35:409-15. Crossref

8. Fess EE. Grip Strength. 2nd Ed. Chicago: American Society of Hand Therapists; 1992.

9. Mathiowetz V, Weber K, Volland G, Kashman N. Reliability and validity of grip and pinch strength evaluations. J Hand Surg Am 1984;9:222-6. Crossref

10. Peolsson A, Hedlund R, Oberg B. Intra- and inter-tester reliability and reference values for hand strength.J Rehabil Med 2001;33:3641. Crossref

11. Sararaks S, Azman AB, Low LL, et al.Validity and reliability of the SF-36: the Malaysian context. Med J Malaysia 2005;60:163-79.

12. Moy F, Chang E, Wee K. Predictors of handgrip strength among the free living elderly in rural Pahang, Malaysia. Iran J Public Health 2011:40:44-53.

13. van Lier AM, Payette H. Determinants of handgrip strength in free-living elderly at risk of malnutrition. Disabil Rehabil 2003;25:1181-6. Crossref

14. Alley DE, Shardell MD, Peters KW, et al. Grip strength cutpoints for the identification of clinically relevant weakness. J Gerontol A Biol Sci Med Sci 2014;69:559-66. Crossref 